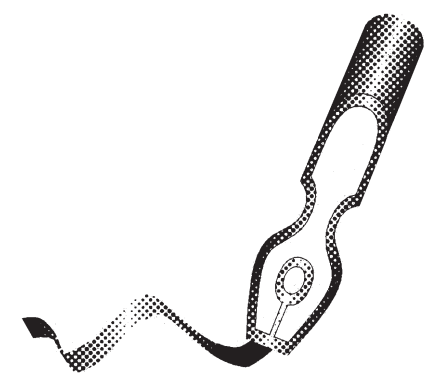

\title{
Desafíos para un nuevo director
}

Recientemente se me ha encomendado el desafío de dirigir nuestra Revista de Otorrinolaringología y Cirugía de Cabeza y Cuello. Agradezco la confianza que la Directiva de la Sociedad Chilena de Otorrinolaringología ha puesto en mi persona para tomar el cargo de Director. Recibo esta responsabilidad, de manos del Dr. Jorge Caro Letelier, quien en los últimos años condujo de manera exitosa la publicación de la revista como lo reflejan sus logros: digitalización e indexación de la revista en SciELO Chile (www.scielo.cl), internacionalización de la revista a nivel hispanoamericano, preservación de su carácter de libre acceso (open access), creación de una plataforma digital para el envío y manejo de los manuscritos por parte de autores, revisores y editores, y un aumento de la frecuencia de publicación de tres a cuatro números anuales.

Asumo el reto de continuar en esta senda, que décadas atrás iniciaron los fundadores de la revista, teniendo como futuros desafíos su indexación en bases de datos Pubmed, Scopus e ISI. Continuaremos renovando la planta de editores con profesionales jóvenes que se sumarán a los experimentados editores que han permitido la publicación ininterrumpida de la revista. También incorporaremos nuevos editores de prestigiosas universidades, hospitales e institutos internacionales. Esperamos mantener un alto estándar ético y académico en la publicación de nuestros artículos, que aporten al desarrollo de la otorrinolaringología y ciencias afines a nivel hispano-americano. Es importante destacar que en el último año hemos recibido trabajos provenientes de Argentina, Chile, Colombia, Ecuador, España, México y Venezuela, entre otros países.

En esta edición de junio, quiero destacar el artículo original de Dadá y Sidat que informa acerca de la realidad del manejo de los cuerpos extraños en el Servicio de Otorrinolaringología del Hospital Central de Maputo en Mozambique. Además, en la presente revista se describen casos clínicos de alto interés en patologías de oído, nariz y laringe. Finalmente, Barría y cols. presentan la revisión del tema de tos persistente y neuropatía laríngea, mientras que Boettiger y cols. revisan el uso del PET-TC en otorrinolaringología. Espero que disfruten de este nuevo número de la revista, y los invito a continuar enviando sus trabajos originales, casos clínicos y artículos de revisión que tanto contribuyen al desarrollo de nuestra disciplina. 